\title{
To Study Applications of Agricultural Drones in Irrigation and Agriculture
}

\author{
Kavita Khadse \\ Chetana's Ramprasad Khandelwal Institute of Management \& \\ Research, Affiliated to Mumbai University, Mumbai, India \\ Corresponding author email: kavita.khadse@crkimr.in
}

\begin{abstract}
Current agribusiness is driven by constant upgrades in computerized instruments and information just as coordinated efforts among ranchers and analysts across the general population and private areas. During the Green Revolution during the 1960s, India could accomplish independence in food grain creation by utilizing current strategies for farming like better nature of seeds, legitimate water system, compound composts and pesticides. As time passed, more mechanical advances showed up in farming. The farm vehicle was presented, trailed by new culturing and collecting gear, water system and air cultivating innovation, all prompting better returns and improved nature of the food and fibre that was developed. It is feasible for ranchers to use logical information and innovation to improve crop yields and stay up with the latest with state-of-the-art techniques for cultivating. In horticulture, enormous information is frequently seen as a mix of innovation and examination that can gather and arrange novel information and interaction it's anything but a more helpful and ideal approach to help dynamic. Rural robots permit ranchers to acquire admittance to an abundance of information they can use to settle on better administration choices, improve crop yields, and increment generally speaking benefit. Robots can be utilized to gather information identified with crop yields, domesticated animals' wellbeing, soil quality, supplement estimations, climate and precipitation results, and then some. This information would then be able to be utilized to get a more precise guide of any current issues, just as make arrangements dependent on very solid information. Robot examination incorporates properties, for example, soil pH, saltiness, and surface, just as incline, H2O accessibility, and peril can be assessed dependent on the planning results.
\end{abstract}

\section{KEY WORDS: AGRICULTURAL DRONES, IRRIGATION, CROP MONITORING, CROP HEALTH ASSESSMENT.}

\section{INTRODUCTION}

Current homesteads and agrarian tasks work far uniquely in contrast to those years and years prior, fundamentally on account of headways in innovation, including sensors, gadgets, machines, and data innovation. The present horticulture regularly utilizes refined innovations like robots, temperature and dampness sensors, aeronautical pictures, and GPS innovation. These high-level gadgets and accuracy farming and mechanical frameworks permit organizations to be more beneficial, effective, more secure, and all the more harmless to the ecosystem.

Biosc Biotech Res Comm P-ISSN: 0974-6455 E-ISSN: 2321-4007

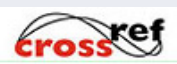

Identifiers and Pagination

Year: 2021 Vol: 14 No (9) Special Issue

Pages: $81-86$

This is an open access article under Creative

Commons License Attribn 4.0 Intl (CC-BY).

DOI: $h t t p: / / d x$.doi.org/10.21786/bbrc/14.9.18
Soil and Field Analysis: Soil reviewing, or ordering regions that share comparative soil properties, assumes a significant part in cultivating and horticulture. Properties, for example, soil $\mathrm{pH}$, saltiness, and surface, just as incline, $\mathrm{H} 2 \mathrm{O}$ accessibility, and disintegration risk can be assessed dependent on the planning results. Robots can be instrumental toward the beginning of the yield cycle. They produce exact 3-D guides for early soil investigation, valuable in arranging seed planting designs. Subsequent to planting, drone-driven soil investigation gives information to water system and nitrogen-level administration. A robot, hook to soil investigation.

Planting: These frameworks shoot cases with seeds and plant supplements into the dirt, giving the plant every one of the supplements important to support life. Initial, a robot examines the geography to make a 3D guide. Then, at that point, the most proficient planting design for that space is determined utilizing calculations. A robot
Article Information

Received: $16^{\text {th }} \mathrm{Apr} 2021$

ccepted after revision: $13^{\text {th }}$ June 2021 
stacked with sprouted seeds fires units into the ground at a pace of one every second, or around 100,000 per day. Scale this up and 60 robot groups could plant 1 billion trees every year.

Crop Spraying: Distance-estimating hardware-ultrasonic repeating and lasers like those utilized in the lightlocation and going, or LiDAR, technique-empowers a robot to change height as the geology and topography differ, and in this manner stay away from crashes. Subsequently, robots can check the ground and shower the right measure of fluid, tweaking distance from the beginning splashing progressively for even inclusion. The outcome: expanded effectiveness with a decrease of in the measure of synthetics entering into groundwater. Indeed, specialists gauge that flying splashing can be finished up to multiple times quicker with drones than with customary apparatus.

Crop Monitoring: Harvest Monitoring drone was shown in figure 6. Tremendous fields and low proficiency in crop checking together make cultivating's biggest impediment. Checking difficulties are exacerbated by progressively flighty climate conditions, which drive hazard and field upkeep costs. Already, satellite symbolism offered the most exceptional type of observing. Yet, there were disadvantages Images must be requested ahead of time, could be required just once every day, and were loose. Further, administrations were very expensive and the pictures' quality ordinarily endured on specific days. Time-arrangement movements show the exact improvement of a trim and uncover creation failures, empowering better yield the board. Besides, exorbitant satellite pictures utilized in the past expected pictures to be requested ahead of time and could just catch one photograph a day. Customarily, the photograph quality was low, on account of environmental conditions and satellite areas. Today, robots can give time-arrangement activities for a portion of the expense, uncovering creation failures and constant advancement of a yield.

Irrigation: Robots with hyperspectral, multispectral, or warm sensors can recognize what parts of a field are dry or need enhancements. Moreover, when the yield is developing, drones permit the estimation of the vegetation list, which portrays the general thickness and wellbeing of the harvest, and show the warmth signature, the measure of energy or warmth the yield radiates. Water system drone is introduced in Drones equipped with warm, hyperspectral or multispectral sensors can rapidly recognize which yields are dry. Moreover, robots can likewise figure the thickness and strength of the edit and give the warmth signature, cautioning the rancher which yields are needing more water and which harvests need less. This proficient utilization of water is a huge expense saving measure when water costs rise and dry seasons strike a district Careful water system additionally lessens the odds of compost spillover into streams and waterways, forestalling the pointless demise of oceanic life and hazardous green growth blossoms.

Health Assessment: Wellbeing evaluation drone is fundamental to survey crop wellbeing and spot bacterial or contagious contaminations on trees. By examining a harvest utilizing both noticeable and close infrared light, drone-conveyed gadgets can recognize which plants reflect various measures of green light and NIR light. This data can deliver multispectral pictures that track changes in plants and show their wellbeing. A rapid reaction can save a whole plantation. What's more, when an infection is found, ranchers can apply and screen cures all the more absolutely. These two prospects increment a plant's capacity to beat infection. Also, on account of yield disappointment, the rancher will actually want to archive misfortunes all the more effectively for protection claims. Utilizing both apparent and close infrared light, robots can recognize plants reflecting various measures of NIR and green light. The multispectral pictures delivered would then be able to represent track changes in the plants and give a sign of their general wellbeing.

Usage of Technology In The Agricultural Sector: Agribusiness needs compelling use of innovation to speed up creation and employability of people. The primary motivation behind this examination paper is to see, how to utilize advancements in the rural area. There are various sorts of innovations that are utilized to improve efficiency. The fundamental regions that have been considered are, factors identifying with selection of innovations, sorts of advances, advances utilized in the rural area, progressed farming advances utilized in the current presence, spaces of data innovation and job of data innovation in rural instruction the executives. For proficient development and improvement of the rural area, there is a need to acquaint with new advancements, similar to biotechnology, nanotechnology, cutting edge ensured development and current water system strategies to speed up creation.

These advancements, when used in a proper way, would end up being advantageous in improving usefulness and productivity. Utilization of innovation would upgrade in supporting occupation openings for the ranchers. Farming is viewed as an essential control of the people in country regions. To take care of the expanding populace, it is fundamental to present current and creative methods in the farming area. New advances are needed to urge the yield wildernesses to a high level stage, utilize the data sources ingeniously and enhance to a more supportable and higher worth trimming designs. These are all information concentrated advances that require both a solid examination and augmentation framework and gifted ranchers. What's more, it's anything but a fortified interface, where accentuation is put on mutual trade of data, carrying benefits to all. Utilizing assets in a powerful way is expressed as the main thrust behind the utilization of horticultural advances.

A few asset preservation advances are, green fertilizer, crop revolutions and so forth The meaning of utilization of innovation in the farming area has been perceived with the principle motivation behind gathering the food necessities of the people. India has gained ground in 
agribusiness, however efficiency of the major rural and plant crops is low in contrast with different nations. There are still shortages in the use of innovation. Yields per hectare of food grains, products of the soil inside the nation are far the underneath worldwide midpoints. Indeed, even India's most useful states are behind the worldwide normal. Additionally, the efficiency of heartbeats and oilseeds can be expanded, through offering thought to the seeds, soil wellbeing, bother the board, crop life-saving water system techniques and post-collect innovation.

Literature Review: Farming is the main business for the utilization of robots. Given the tremendous number of hectares of land that are offered over to horticultural exercises and the distance (for example absence of wired or Wi-Fi foundation), this is maybe to be expected. Robots are cheap and dependable. What has been missing up to now is the capacity to add significant experiences into the information caught by rambles. The difficulties to doing this effectively have been demonstrated to be:

1. Preparing the huge measures of information caught (5 000 PCs worth in one month for 20 sensors at 1 $\mathrm{Hz}$ for a normal homestead); E-agribusiness in real life: Drones for Agriculture 55 Actionable insight from robots to the rural business

2. Coordinating numerous information sources on various conventions (for example GIS information, different sensor sellers, pre-preparing of picture information);

3. Investigating the resultant datasets in an ideal way to deliver noteworthy experiences; and

4. Introducing the significant experiences in a way that can be seen without any problem.

SAP has brought three of its innovations together to empower the data catch by robots to be powerful. These innovations are:

(1) The HANA cloud data set innovation with boundless rapid information catch, recovery and investigation; (2) the Leonardo IoT suite to associate and trade data over any convention; and (3) the Connected Agriculture suite to give an instinctive and graphical front finish to ranchers and cultivators. The exercises of the utilization cases can be stretched out to any farming test. In spite of the fact that tree/shrub manors and steers grouping were the models given here, any farming administration and choice help issue can be addressed with this vigorous, develop and fit for reason innovation.

The job of reconnaissance in horticulture shows extraordinary guarantee, for example, in natural fiasco counteraction in ranger service and ranch plant assurance, fisheries and so forth Thusly, minimal expense, constant, huge scope and stable observation, precise information obtaining and transmission just as preparing are extremely essential for horticulture creation and catastrophe anticipation. Nonetheless, in most country regions the shortfall of remote base stations and WiFi stations is a significant obstruction in carrying out reconnaissance frameworks. That implies the information procured through the Wireless Sensor Network (WSN) can't be sent utilizing remote correspondences. An elective arrangement is to utilize UAV to speak with the WSN in huge regions to get constant information for handling and examination. There are WSN networks that consolidate many Zigbee hubs that are associated with sensor modules, and which then, at that point speak with the UAV that is outfitted with one Zigbee hub. Each Zigbee hub can cover a range of $200 \mathrm{~m}$ to $500 \mathrm{~m}$ of land along these lines many hubs can really cover around 1000 to 2000 sections of land of ranch. Every sensor module comprises of up to ten sensors for soil and climate data, for instance soil temperature, soil stickiness, soil manure, daylight power, CO2, soil PH esteem, downpour force, wind power. The information procured will then, at that point be sent from the organizer inside the WSN to the UAV side for information assortment.

Challeges: One of the difficulties is the harmony between the UAV cost and the exhibition. Superior of the UAV with long flight time, solidness, just as restricted obstruction will be costly and keep ranchers from receiving the application as they are impervious to any new expenses. The subsequent test is that ranchers need time to acknowledge new innovation and to be persuaded those benefits from this plan are ensured.

Learnings: These UAV-based strategies will improve ranch creation productivity altogether with an ever increasing number of utilizations, which have shown exceptional upgrades for enormous homestead information securing contrasted with ordinary homestead observation. Notwithstanding, the UAV-based reconnaissance actually needs to address difficulties like soundness in poor natural and climate conditions. Subsequently, the UAVbased WSN is a promising innovation and an elective that will accomplish minimal expense, wide-running correspondence, continuous, dependable information procurement when the base station isn't free. UAV-WSN based observation framework is applied broadly sooner rather than later, a great many ranchers will actually want to profit with the obtaining of ongoing homestead data. Ranchers won't have to invest a lot of energy on obtaining ranch information and will approach debacle cautioning and climate data when a fiasco occasion appears to be conceivable. By and by, the UAV-WSN innovation is as yet not develop enough for huge scope application. More UAV-WSN innovative work is required, including the advancement of utilizations for fishing, poultry and cultivating ventures.

One of fundamental kind of revenue in of India is Agriculture. The creation pace of harvests in farming depends on different boundaries like temperature, stickiness, downpour, and so forth Which are regular elements and not in rancher's control. The field of agribusiness is likewise relying upon some of elements like irritations, illness, composts, and so on which can be control by giving appropriate treatment to crops. Pesticides may build the efficiency of harvests however it additionally impacts on human wellbeing. So the 
fundamental point of this paper is to plan farming robot for showering pesticides. In this paper, we will examine diverse design dependent on automated flying vehicles (UAVs).

The utilization of pesticides in agribusiness is vital to horticulture and it will be so natural if will utilize keen machines, for example, robots utilizing new innovations. This paper gives the thought regarding different innovations used to lessen human endeavors in different tasks of horticulture like location of essence of vermin, splashing of UREA, showering of composts, and so forth This paper depicts the advancement of quad copter UAV and the showering component. In this paper we additionally talk about mix of sprayer module to quad copter framework. The examined framework includes planning a model which utilizes straightforward financially savvy hardware like BLDC engine, Arduino, ESC wires, and so forth.

\section{Monitoring and controlling crop irrigation systems via} smartphone: Mobile technology is playing an important role in monitoring and controlling crop irrigation systems. With this modern technology, a farmer can control his irrigation systems from a phone or computer instead of driving to each field. Moisture sensors in the ground are able to communicate information about the level of moisture present at certain depths in the soil.

2. Ultrasounds for livestock: Ultrasound is not only for checking on baby animals in the womb. It also can be used to discover what quality of meat might be found in an animal before it goes to the market. The testing of DNA helps producers to identify animals with good pedigrees and other desirable qualities. This information can also be used to help the farmer to improve the quality of his herds.

3. Usage of mobile technology and cameras: Some farmers and ranchers use apps like 'Foursquare' to keep tabs on employees. They also put-up cameras around the farm. Livestock managers are wiring up their barn feedlots and pastures with cameras that send images back to the central location like an office or home computer. They can keep a closer eye on the animals when they are away or home for the night.

4. Crop Sensors: Crop sensors help apply fertilisers in a very effective manner, maximising uptake. They sense how your crop is feeling and reduce the potential leaching and runoff into ground water. Instead of making a prescription fertiliser map for a field before you go out to apply it, crop sensors tell application equipment how much to apply in real time. Optical sensors are able to see how much fertiliser a plant may need, based on the amount of light reflected back to the sensor.

Vision about modern agriculture: Horticulture is the main business for the use of robots. Given the tremendous number of hectares of land that are offered over to agrarian exercises and the distance (for example absence of wired or Wi-Fi framework), this is maybe to be expected. Robots are cheap and solid. What has been missing up to now is the capacity to add significant bits of knowledge into the information caught by rambles. The difficulties to doing.

\section{Objectives}

- To study the collection soil samples in various regions with the aid of GPS (global positioning system) coordinate and analyse the field condition with the help of drone.

- To monitor the forest and identify changes in specific points of forest cover undergoing deforestation and degradation processes, to monitor the status of crops and to monitor invasions of territory.

- To calculate the vegetation index, which describes the relative density and health of the crop, and show the heat signature, the amount of energy or heat the crop emits.

- To study the efficiency with a reduction of in the amount of chemicals penetrating into groundwater.

\section{RESEARCH METHODOLOGY}

This paper is based on published resources. The nature of the study is Exploratory analysis. After careful analysis this study explores the role of agricultural drones in irrigation and agricultural. The agriculture industry is no stranger to embracing changing technological trends to streamline business. The use of drones in agriculture will help agricultural businesses meet the changing and growing demands of the future. Agricultural Drones Ground-based and aerial-based drones are being used in agriculture in order to enhance various agricultural practices: crop health assessment, irrigation, crop monitoring, crop spraying, planting, and soil and field analysis.

Analysis And Findings: Horticulture Wonder Drone System utilizing miniature regulator 8051 The proposed framework is an inserted framework which will intently screen and control the microclimatic boundaries of a nursery consistently nonstop for development of harvests or explicit plant species which could amplify their creation over the entire yield development season and to dispose of the troubles engaged with the framework by decreasing human intercession to the most ideal degree. The framework contains sensors, Analog to Digital Converter, microcontroller and actuators. At the point when any of the previously mentioned climatic boundaries pass a wellbeing boundary which must be kept up to ensure the harvests, the sensors sense the change and the microcontroller peruses this from the information at its info ports in the wake of being changed over to a computerized structure by the ADC.

The microcontroller then plays out the required activities by utilizing transfers until the wandered out boundary has been taken back to its ideal level. Since a microcontroller is utilized as the core of the framework, it makes the set-up minimal expense and powerful by and by. As the framework additionally utilizes a LCD show 
for constantly alarming the client about the condition inside the nursery, the whole arrangement becomes easy to use. Hence, this framework dispenses with the downsides of the current set-ups referenced in the past area and is planned as a simple to keep up, adaptable and minimal expense arrangement. The cutting edge cultivating industry is at a defining moment. With the improvement of further developed ranch the board strategies, like exactness farming, industry experts presently have more instruments than any time in recent memory to improve the precision and proficiency of cycles. The utilization of the various sorts rural robots for settling explicit assignments of plant developing is considered: production of electronic guides of fields, operational observing of harvest conditions, assessment of germination and foreseeing crop yields, checking the nature of furrowing, keeping up ecological checking of agrarian land, and so forth Thus, drones are vital devices in the cutting edge horticulture and cultivating frameworks.

Robots are utilized in a wide scope of errands like coordinations undertakings, watch regions, framework support, maps age utilizing cameras or sensors. A considerable lot of the stages utilize associated drones as teleoperated vehicles through the web, putting together the framework correspondence with respect to low even out administrations straightforwardly identified with the robot essential developments or orders. Environmental change is significantly affecting food security. Cultivating people group and others associated with horticulture need to adjust farming to environmental change and different difficulties. Current administration in practical agribusiness requires the quick data about state of developed plants and the speedy reaction to unwanted events. Essential reason and the utilization of robots for showering plants could be considering quick use of plant insurance specialists on the developing regions. Likewise, paper presents the pertinent sorts, job and meaning of robot's use in the cutting edge agribusiness.

Perhaps the most recent improvement is the increment in the utilization of little, automated ethereal vehicles or distantly guided airplane framework, normally known as robots, for horticulture. Robots, can change from light, straightforward, short-range vehicles, radio controlled in visual view of the administrator, to huge scope airplane, tele-worked abroad through satellite connection. For example, the Northrop Grumman "Worldwide Hawk", can fly at an elevation more than 65,000 feet, outfitted with sensors to see through mists or in complete haziness. A wide scope of revolving wing stages is additionally being used and creation, particularly smaller than normal helicopters for neighborhood observation or discovery. Now and again, drones can gather information significantly more effectively than either satellites or monitored airplane at any point could. The mission relies upon the payload and the ground station ability to gather, measure and disperse information for the mission's targets. Robots can gather high-goal pictures and recordings, phone discussions, catch electronic interchanges and some other wave or sign contingent upon the payload introduced ready.

They can likewise perceive faces, or even recognize "unusual practices" and distinguish human targets. Future sun oriented force robots will actually want to remain noticeable all around perpetually, turning into a nonstop reconnaissance apparatus in the hand of public specialists. There is no uncertainty that robots may address a genuine danger to the protection right. The utilization of robots in horticulture is reaching out at a lively speed in crop creation, early admonition frameworks, debacle hazard decrease, ranger service, fisheries, just as in untamed life preservation. For instance, drone innovation will give the farming business a high-innovation makeover, with arranging and methodology dependent on ongoing information assembling and handling following: soil and field investigation, planting, crop showering, crop observing, water system, and wellbeing evaluation.

Agrarian innovation can influence smallholder pay, work openings for poor people, food costs, ecological manageability, and linkages with the remainder of the country economy:

- Agricultural innovation has been an essential factor adding to expansions in ranch efficiency in non-industrial nations over the past 50 years. Despite the fact that there is as yet broad food frailty, the circumstance without current innovation improvement would have been inconceivable.

- New innovation can give extra provincial work, yet there are continually countervailing pressing factors to decrease work information and lower its expenses.

- Food costs are certifiably lower due to innovation, yet the dispersion of advantages among shoppers and makers relies upon the idea of the nearby economy and exchange designs.

Quite possibly the most troublesome decisions is that confronting the fitting degree of (rural) support for neediness decrease in minimal regions. A significant test is marshaling adequate (and sound) support for public examination and expansion notwithstanding extreme imperatives being developed financial plans. Private area innovation age (and innovation conveyance) is of developing significance to destitution decrease techniques, however it is likely nonsensical to put exclusive requirements on limitlessly extended conventional public-private organizations. Sensors are machines that can detect for example sound, light and weight without direct contact with the item. Sensor innovation is additionally helpful for the assurance of the organization or potentially the nature of food. The agro and food area utilizes sensor innovation to gather information on the dirt, harvests and creatures through sensors that are incorporated in a wide range of farming hardware and machines, airplane and drones or even satellites. Sensors furnish ranchers with ongoing data 
on their harvests and domesticated animals, empowering them to react all the more successfully, for example by taking (restorative) measures. Sensor innovation can be utilized to build up item quality and security, yet for example additionally the beginning. Instances of sensor innovation in farming incorporate airborne.

Brilliant cultivating is horticulture in which the yield, creatures and soil get the specific treatment that they need. Other than in conventional agribusiness, in shrewd cultivating the rancher takes a gander at the need per plant or animal rather than per field or group. Considering the particular states of the dirt, long stretches of daylight and environment will improve the yield. Compelling shrewd cultivating depends on information examination. Regarding the yields and creatures as precisely and successfully as conceivable requires a few center components - like programmed discovery - to decide the variety in soil, harvest and creature conduct.

\section{CONCLUSION}

Drones can scan the ground and spray the correct amount of liquid, modulating distance from the ground and spraying in real time for even coverage. Aerial spraying can be completed up to five times faster with drones than with traditional machinery. These systems shoot pods with seeds and plant nutrients into the soil, providing the plant all the nutrients necessary to sustain life. First, a drone scans the topography to create a 3D map. Then, the most efficient planting pattern for that area is calculated using algorithms. A drone loaded with germinated seeds fires pods into the ground at a rate of one per second, or about 100,000 a day. Scale this up and 60 drone teams could plant 1 billion trees a year.

\section{REFERENCES}

Gerard Sylvester (2018), Food and Agriculture Organization of the United Nations and International Telecommunication Union Bangkok

Swapnil Kurkute ( 2018), Drone for smart agriculture technical report.

Technology And Its Contribution to Pro-Poor Agricultural Development, Agriculture And Natural Resources Team of The UK Department For International Development (DFID) In Collaboration With Rob Tripp of ODI, London.

Yuwalee Unpaprom, Natthawud Dussadeeb , Rameshprabu Ramaraj, (2018), In book: Modern Agriculture Drones (pp.13-19) Chapter: Modern Agriculture Drones the Development of Smart Farmers

http://www.oecd.org/greengrowth/sustainableagriculture/2739771.pdf

https://en.wikipedia.org/wiki/Agricultural_drone https://nifa.usda.gov/topic/agriculture-technology https://www.cropin.com/blogs/agriculture-4-0-howtechnology-is-helping-build-digital-farms-of-thefuture/

https://www.downtoearth.org.in/blog/agriculture/ applying-modern-tech-to-agriculture-66017

https://www.equinoxsdrones.com/blog/importance-ofdrone-technology-in-indian-agriculture-farming https://www.precisionag.com/in-field-technologies/ drones-uavs/the-role-of-drone-technology-insustainable-agriculture/

https://www.sourcetrace.com/blog/new-agriculturetechnology/ 